\title{
Aproximación a la conservación del arte de Internet: la materia como relaciones comunicativas
}

\author{
Antonio J. Sánchez Fernández \\ Doctor por la Universidad de Sevilla. Conservador-Restaurador de Bienes Culturales \\ Eduardo Martínez Pérez \\ Conservador-Restaurador de Bienes Culturales. Perito Judicial en Arte y Antigüedades
}

RESUMEN:

Esta investigación tiene como objetivos, por un lado, exponer determinadas estrategias para la conservación y restauración del arte de Internet, y, por otro, ofrecer una aproximación a la definición, fases y tipos de manifestaciones. La concepción de "arte de Internet" engloba una variedad de expresiones que comparten un mismo soporte e idénticos planteamientos de documentación, exposición, almacenamiento y/o mantenimiento. Además, la noción de net art se impone como término globalizador. Asimismo, se ha reconstruido el desarrollo en el tiempo de esta tipología artística. También exponemos varios casos de restauración y ejemplos de técnicas de conservación realizadas en instituciones de referencia. Igualmente, resultó esencial tratar de definir la autenticidad conceptual como requisito fundamental para abordar toda intervención. En este sentido, observamos cómo las particularidades inmateriales se constituyen como una nueva "materialidad". Así, determinamos la relación de compatibilidad entre la estrategia de conservación-restauración y el mantenimiento del significado de la obra de arte.

PALABRAS CLAVE:

Conservación; restauración; arte de Internet; net.art

\section{ABSTRACT:}

This research project sets out, on one hand, to describe certain strategies for the preservation and restoration of Internet art, and, on the other hand, to provide an approach to the definition, phases and types of manifestations. The concept of Internet art encompasses a variety of expressions that share the same format and identical approaches to documentation, exhibition, storage and/or upkeep. What is more, the notion of net art is the generally accepted term. Likewise, the development of this type of art has been reconstructed over time. We also describe several cases of restoration and examples of preservation techniques carried out at benchmark institutions. It was also essential to attempt to define conceptual authenticity as a fundamental requirement to address any type of intervention. In this sense, we observe how immaterial peculiarities become a new "materiality". As a result, we define the compatibility between the preservation-restoration strategy and the constant meaning of the work of art.

KEYWORDS:

Conservation; Restoration; Internet Art; net.art 


\section{Introducción}

El objetivo de este estudio se centra en una aproximación a los problemas de conservación del arte de Internet. No obstante, la cercanía en el tiempo, la popularización de términos o la multitud de manifestaciones, hacen que falte perspectiva y curado de este movimiento. También, proponemos una casuística de estrategias de conservación y restauración. En este sentido, se exponen diversos ejemplos de restauración. Sin embargo, por las características de esta tipología de arte, resulta complejo establecer un único patrón de conservación, y, además, es imprescindible un enfoque interdisciplinar. Así, permanece un enfrentamiento entre el carácter intangible y la necesidad de su conservación. No constan criterios o protocolos a seguir, puesto que existen unas variables complejas: multitud de técnicas, métodos e intenciones de los artistas, etc. Así, tratamos de establecer un marco de reflexión desde el conocimiento de la historia del arte de Internet hasta las posibilidades de las estrategias de conservación.

En definitiva, el patrimonio digital, en general, aglutina elementos "que son fruto del saber o la expresión de los seres humanos. A menudo son efímeros, y su conservación requiere un trabajo específico"'. Así, en 2003 coinciden dos documentos promulgados por la UNESCO ${ }^{2}$ : la "Convención para la salvaguardia del patrimonio cultural inmaterial" y "Carta sobre la preservación del patrimonio digital”, indicativo de la vinculación de ambos aspectos y que establecemos como marco conceptual de nuestra investigación.

Por otro lado, destacamos el trabajo de Gema Grueso Otalo que además de reflexionar sobre los giros de la definición de arte de Internet $^{3}$, también se cuestiona el nuevo papel de

UNESCO, Carta sobre la preservación del patrimonio digital, 2003a, [en línea] recuperado de: http://portal. unesco.org/es/ev.php-URL_ID $=17721$ \&URL_DO =D0_ TOPICEURL_SECTION=201.html

2 UNESCO, Carta sobre la preservación..., opus cit. y UNESCO, Convención para la salvaguardia del patrimonio cultural inmaterial, 2003b, [en línea] recuperado de: http://portal.unesco.org/es/ev.php-URL ID $=17716 \&$ URL_DO=DO_TOPICEURL_SECTION=201. html

3 GRUESO OTALO, Gema, ¿Qué es el Net.Art? Del Net. Art al Arte de Internet, 2012, [en línea] recuperado de: https://sites.google.com/site/netartpfmggrueso/home/que-es-el-net-art la figura del conservador-restaurador ${ }^{4}$. Igualmente, Claudia Giannetti ${ }^{5}$ aporta su visión de la evolución del net art y la problemática de la conservación del patrimonio digital, al igual que Rachel Greene $^{6}$. Por último, Rivero Moreno ${ }^{7}$ estudia los problemas de conservación del arte de los nuevos medios. Asimismo, sobresale la experiencia de Rhizome y The New Museum ${ }^{8}$ y Guggenheim Museum ${ }^{9}$, en la restauración de piezas de net art.

\section{Aproximación a una definición del arte de Internet}

Varios autores coinciden en destacar la dificultad de una catalogación de las múltiples manifestaciones artísticas que suele englobar el arte de Internet ${ }^{10}$.

Encontramos unos precedentes, en su instancia conceptual, en el interés de utilizar los medios de comunicación de forma creativa en algunos artistas dadaístas y constructivistas ${ }^{11}$. No obstante, el hecho fundamental reside en el diseño de Internet como medio de comunicación global. En 1990 se crea la aplicación World Wide Web por Berners-Lee constituyendo una red de comunicación de acceso libre, potenciado con la implantación del navegador Mosaic, al que le seguirá Netscape Navigator, como el primer navegador comercial, y otros navegadores de libre acceso.

GRUESO OTALO, Gema., "Redefiniendo la labor del conservador-restaurador”, en PH: Boletín del Instituto Andaluz del Patrimonio Histórico, $\mathrm{n}^{\circ}$ 86, 2014, pp. 173-174. GIANNETTI, Claudia, "Breve balance de la primera década del net art", en Red digital: Revista de Tecnologías de la Información y Comunicación Educativas, $\mathrm{n}^{\circ}$ 3, 2002, [artículo en línea] recuperado de: http://reddigital.cnice.mec.es/3/firmas/firmas_claudia_ind.html

6 GREENE, Rachel, "Web work: a history of internet art", en ARTFORUM International, $\mathrm{n}^{\circ}$ 9, 2000, pp. 162-167, 190.

7 RIVERO MORENO, Luis D., "Inmaterialidades. Problemas de conservación del arte de los nuevos medios”, en De Arte, no 16, 2017, pp. 227-238.

8 NEW MUSEUM Y RHIZOME, Net Art Anthology, New York, 2018, , [en línea] recuperado de: https://anthology.rhizome.org/

9 THE GUGGENHEIM MUSEUMS AND FOUNDATION, Brandon. 2016-2017 Restoration, New York, 2017, [en línea] recuperado de: http://brandon.guggenheim.org/ credits/

10 RODRÍGUEZ IBÁÑEZ, Margarita, "El concepto de Net. art....., opus cit.; GRUESO OTALO, Gema, ¿Qué es el Net.Art?..., opus cit.

11 GIANNETTI, Claudia, "Breve balance de..., opus cit. 
Sin embargo, en la década de los setenta existió una tendencia a crear proyectos creativos usando las telecomunicaciones, como: Cadaqués Canal Local de Antoni Muntadas en 1974; Nine Minutes Live de Nam June Paik, en 1977 o Two Way-Demo de Sharp, Bear, Grace y Loeffler, en $1977^{12}$.

Entre los ochenta y principios de los noventa, se potenció el uso creativo de las redes telemáticas con el objetivo de explorar modos de interacción y crear espacios virtuales que favorecieran la creación de obras artísticas ${ }^{13}$. Una parte representativa de estas manifestaciones ya tenían un marcado acento social y la participación de los usuarios como elemento protagonista, características recurrentes que se mantendrán en el tiempo. Así, destacaron la red en torno a Roy Ascott, Terminal Consciousness; propuestas que se servían de teleconferencias, mailboxes o televisión interactiva, como Electronic Cafe Internacional de Kit Galloway y Sherrie Rabinowitz; ArtCom Electronic Network-ACEN de C. Loeffler, Bionic de Rena Tangens y Padeluun o BBS-mailbox; pARTiciFAX, Ponton/Van Gogh TV de Ponton Media, Documenta 8; Fax Station de Marisa Gonzáles o Telage de Carlos Fadon Vicente ${ }^{14}$.

\subsection{Conceptualización del arte de Internet: Net art como manifestación artística y término globalizador}

El Plan Nacional de Conservación del Patrimonio Cultural del Siglo XX reconoce al arte de Internet como una de las tipologías de artes plásticas dentro su alcance (Arte en la Red, también conocido como net art). El término net art $^{15}$ surge a mediados de la década de los noventa de la experiencia del artista Vuk Cosic que recibió un correo electrónico incomprensible, por la incompatibilidad de software. El mensaje era un manifiesto de un artista que pronosticaba la obsolescencia del arte por la utilización de la Red ("All this becomes posible only with the emergence of the Net. Art as a

\footnotetext{
GIANNETTI, Claudia, "Breve balance de..., opus cit. GIANNETTI, Claudia, "Breve balance de..., opus cit. GIANNETTI, Claudia, "Breve balance de..., opus cit.

15 GREENE, Rachel, "Web work..., opus cit.; RODRÍGUEZ IBÁÑEZ, Margarita, "El concepto de Net.art.: la fuerza del grupo conectado", en AACADigitalRevista de la Asociación Aragonesa de Críticos de Arte, n 18, 2012, [en línea] recuperado de: http://www.aacadigital.com/ contenido.php?idarticulo=612.
}

notion becomes obsolete"). Entre el caos alfanumérico, (...) J8 g\# ||;Net.Art\{-^s1 (...), Cosic encontró el término “net.art” que utilizó para nombrar al arte de la red y las comunicaciones.

No obstante, para Grueso Otalo ${ }^{16}$ el término net art sólo hace referencia a una serie de autores en un corto período de tiempo y para unas obras concretas. Sin embargo, el término se populariza y absorbe a toda la variedad de manifestaciones artísticas que utilizan la Red. Por esta razón, algunos autores ${ }^{17}$ optan por usar la expresión "arte de Internet”. Así, se concibe como "la actividad artística que se produce para y se desarrolla en la red y que explora o aprovecha sus características específicas"18.

Para Barbaño y Muñoz-Muñoz ${ }^{19}$, mientras el arte en Internet hace referencia a cualquier obra que pueda ser visualizada en este medio, el concepto net art comprende a todas las obras de arte creadas para y desde Internet. Los artistas utilizan la velocidad de comunicación, distribución de información, y las reacciones, sensaciones y respuestas del receptor.

El net art se entiende como un arte que utiliza un soporte digital, sujeto a los parámetros de un sistema interactivo, hipertextual, unimedia, ubicuo y personalizado ${ }^{20}$. Los net-artistas establecieron un nuevo orden pues la exhibición de la obra prevalece como valor frente a su apropiación $^{21}$. Así, las obras de net art pueden disfrutarse sin restricciones temporales o geográficas, sólo se necesita un ordenador conectado a Internet y un navegador (browser). En cuestiones de mercado de arte, lo que se adquiere es el derecho a su propiedad intelectual, la cesión de derechos, comprando el dominio donde se aloja ${ }^{22}$.

16 GRUESO OTALO, Gema, ¿Qué es el Net.Art?..., opus cit.

17 GREENE, Rachel, "Web work..., opus cit.; CILLERUELO GUTIÉRREZ, Lourdes, Arte de internet: Génesis y definición de un nuevo soporte artístico (1995-2000) (Tesis Doctoral), Universidad del País Vasco - Euskal Herriko Unibertsitatea, 2000; GRUESO OTALO, Gema, ¿Qué es el Net.Art?..., opus cit.

18 GRUESO OTALO, Gema, ¿Qué es el Net.Art?..., opus cit.

19 BARBAÑO GONZÁLEZ-MORENO, María y MUÑOZ-MUÑOZ, Ana M., "La construcción de la imagen de las mujeres: net.art y medios de Comunicación”, en Historia y Comunicación Social, Volúmen 1, número 22, 2017, p. 251. DOI: 10.5209/HICS.55911.

20 RODRÍGUEZ IBÁÑEZ, Margarita, "El concepto de Net. art.:..., opus cit.

${ }^{21}$ RODRÍGUEZ IBÁÑEZ, Margarita, "El concepto de Net. art....., opus cit.

22 BARBAÑO GONZÁLEZ-MORENO, María y MUÑOZ-MUÑOZ, Ana M., "La construcción de la imagen..., opus cit., p.251. 
De esta forma, aceptamos el término "arte de Internet” como denominación general para la presente investigación, ya que esta variedad de manifestaciones comparte un mismo soporte e idénticos planteamientos de documentación, exposición, almacenamiento y/o mantenimiento. Sin embargo, reconocemos la expresión net art como sinónimo, dado la difusión de dicho concepto.

\subsection{Fases y generaciones del net art}

Los artistas se iniciaron considerando Internet como espacio autónomo, ingenuamente ajeno a la capacidad de impregnación de los poderes establecidos, defendían la capacidad de conectividad y de acción. Las primeras concepciones entendian que el significado de las obras se construía desde la arquitectura hipertextual, de manera que era el usuario el que decidía el recorrido y el artista, el diseñador de la estructura $^{23}$.

Dependiendo del enfoque podemos advertir varias posibilidades de clasificación, atendiendo a un orden cronológico o por el concepto de relación con el soporte. Así, se proponen las siguientes épocas o fases del net art:

- Preludio (hasta 1991): se formaron grupos en torno a las comunidades virtuales. Se creó el proyecto The Thing, que usaba boletines electrónicos o mailbox y popularizó el lema "the users are the network". Tenía como objetivo actuar como espacio para la comunicación, la distribución y la producción en red de nuevas formas artísticas $^{24}$.

- Primera etapa de la producción online (1993-1994): Mirage creó en 1993 Poem*Navigator, en el que se plantea la noción del viaje hipertextual a partir de un poema. En 1994, destacan una serie de proyectos para Internet: Waxweb, de David Blair (primer proyecto de cine hipertextual en Internet); la Digitale Stad Amsterdam y la Internationale Stadt Berlin; el proyecto The File Room, de Antoni Muntadas; Fluxus Online, de Paul Garrin o Hotpics, de Alexei Shulgin (proyecto de

23 LÓPEZ MARTíN, Elena. y MORGADO AGUIRRE, Borja, "Estrategias artísticas del videoarte y otras imágenes móviles en la cibercultura del siglo XXI. El caso de un Youtube intervenido e interventor", en Arte y políticas de identidad, no 9, 2013, p. 168.

24 GIANNETTI, Claudia, "Breve balance de..., opus cit. fotografía online del www-Art Centre de Moscú) $)^{25}$.

- Comunidades y contenidos (1994 y 1995): Existe una superación del modelo artístico tangible. El principal valor deriva de la propia idea y procesos de innovación encontrados ${ }^{26}$. The Thing, Echo, Nettime, y The Well supusieron puntos de reunión en la Red y las listas de correo y boletines electrónicos (BBS, Bulletin Board System), medios de distribución y promoción. Destacaron los sitios como äda'web, Irational.org y Jodi.org ${ }^{27}$. Esta etapa se caracteriza por la publicación de manifiestos y la creación de polémicas. A partir de la privatización de la Red en 1995, la actitud de los artistas se radicaliza y les lleva a desarrollar obras basadas en el sabotaje y movilizaciones sociales en la Red, en lo que se ha denominado Hacktivismo $^{28}$.

- Plenitud y mantenimiento económico (1995-1998): Los artistas trabajan casi exclusivamente con Internet; se replantean la denominación "arte", la funcionalidad y el determinismo del medio; se realizaron los primeros eventos, muestras y publicaciones específicas. A partir de 1996, se empezó a extender el término net.art en el primer encuentro de artistas europeos que trabajaban con Internet: The Next Five Minutes ${ }^{29}$. En 1996, se producía en Trieste (Italia) la conferencia Net.art Per Se, donde se exploraban caminos para mantenerse económicamente $^{30}$. En 1997, se desarrollaron trabajos como 7-11; Desktop Is (www.easylife. org/desktop); Form Art (www.c3.hu/collection/form); Documenta Done (Vuk Cosik, www.ljudmila.org/ vuk/dx) o $M y$ Boyfriend Came Back From the War de Olia Lialina (www.teleportacia.org/war ), el software Web Stalker del colectivo I/0/D (www.backspace.org/iod/iod4Winupdates.html) y las VNSMatrix ${ }^{31}$.

\footnotetext{
GIANNETTI, Claudia, "Breve balance de..., opus cit.

26 RODRÍGUEZ IBÁÑEZ, Margarita, "El concepto de Net. art.:..., opus cit.

27 GREENE, Rachel, "Web work..., opus cit.

28 LÓPEZ MARTÍN, Elena. y MORGADO AGUIRRE, Borja, "Estrategias artísticas del..., opus cit., p. 173.

29 GIANNETTI, Claudia, "Breve balance de..., opus cit.

30 GREENE, Rachel, "Web work..., opus cit., p. 163.

31 GREENE, Rachel, "Web work..., opus cit., p. 164.
} 
- Popularidad, relevancia y paradoja (1999): con proyectos destacados como Netomat (www.netomat.net) de Maciej Wisniewski; En 1999, los italianos Mattes, conocidos como 0100101110101101.org, clonaron obras de net art propiedad de la galería Hell.com, de acceso privado, liberando las obras (http://www.0100101110101101. org/home/copies/hell.com/index.html) Además, varios artistas comenzaron a comercializar de forma electrónica su obra y construir sus propias galerías en línea, como Olia Lialina (art.teleportacia.org/ art-ns4.html) y John Simon Jr. (www. numeral.com/everyicon.html). El net art había adquirido reconocimiento, como demuestra su inclusión en la Bienal del Whitney $^{32}$. Asimismo, el net art se acerca a los espacios oficiales, a pesar del espíritu anti institucional con el que nació. En esta fase las instituciones comenzaron a incluir obras de net art en sus fondos y también existe un carácter reivindicativo. Se defendía tanto el medio como la figura del "auténtico artística del medio"33.

- Participación como forma de creación: los planteamientos giran en torno al propio concepto de "Red". Se advierten, dos subfases $^{34}$ : Aquella que referencia el cambio en la sociedad por la incorporación de la Red en nuestras vidas. Ejemplificado en manifestaciones como el cyberpunk, que se refiere a la idea del humano-tecnológico o en su evolución, post-cyberpunk, que reflexiona en el cambio que nos provoca la tecnología que la hibridación del hombre y la comunicación instantánea. Y otras dinámicas emergentes, donde la Red es el sujeto, pero ya no el soporte de creación. Por ejemplo, las obras de Muntadas o Rogelio López Cuenca.

El análisis de la artista rusa Olia Lialina resulta muy interesante por la relación que establece entre los artistas y el soporte. Así, existen varias generaciones de net art, no siempre acotadas a un espacio concreto de tiempo ${ }^{35}$ :

32 GREENE, Rachel, "Web work..., opus cit., p. 166.

33 RODRÍGUEZ IBÁÑEZ, Margarita, "El concepto de Net. art...., opus cit.

34 RODRÍGUEZ IBÁÑEZ, Margarita, "El concepto de Net. art....., opus cit.

35 LIALINA, Olia, Net Art Generations, Teleportacia, 2013, [en línea] recuperado de: http://art.teleportacia.org/observation/net_art_generations/
- Artistas que trabajan con Internet como un nuevo medio, procedentes de otros entornos (cine, performance, fotografía, etc.) y que lo perciben como nuevo porque están aplicando sus experiencias anteriores traducidas a este medio.

- Artistas educados en prestar atención a Internet.

- Net artistas activos entre la burbuja puntocom (dot.com crash) y el nacimiento de la web 2.0 (alrededor de los años 20002005).

- Artistas que trabajan con la WWW como medio de comunicación masivo (no como nuevo medio). Estos artistas deben encontrar formas de actuar dentro de los grandes servicios, competir con los aficionados y gestionar la popularidad efímera.

\subsection{Atomización de las manifestaciones del arte de Internet}

El arte de Internet no son las obras artísticas generadas con cualquier medio que usan la red sólo para su distribución. Así, se puede distinguir entre el arte para Internet y el arte en Internet. La primera, define las obras cuya característica principal es "insertarse y apropiarse de la plataforma telemática como contexto, como medio y como lenguaje propio" ${ }^{36}$; la segunda, engloba a "todas aquellas manifestaciones que utilizan Internet en calidad de tecnología de comunicación" ${ }^{37}$.

La concepción de net art se asocia a múltiples manifestaciones que usan las posibilidades de Internet como el arte de software, web art, game art, browser art, arte de correo electrónico, etc. Las características de estas expresiones dificultan una catalogación efectiva, ya que encontramos múltiples variaciones. Un claro ejemplo es la diferencia entre el movimiento de software libre y el de código de fuente abierto (open source): este último no recoge que dicho código se pueda copiar, adaptar o distribuir $^{38}$. Así, ciberactivistas y hackers defendían un código fuente abierto y promovieron desde movilizaciones hasta sabotajes en la $\operatorname{Red}^{39}$. Para

\footnotetext{
GIANNETTI, Claudia, "Breve balance de..., opus cit.

37 GIANNETTI, Claudia, "Breve balance de..., opus cit.

38 BERRY, Josephine, "Código al descubierto: el net art y el movimiento de software libre", en Artnodes, $\mathrm{n}^{\circ}$ 3, 2004, p.4, [artículo en línea], DOI: http://dx.doi.org/10.7238/a.v0i3.691

39 GIANNETTI, Claudia, "Breve balance de..., opus cit.
} 
Josephine Berry, "la idea de invento original es uno de los límites a la analogía entre el movimiento de software libre y el net art: mientras que es posible escribir el código completo desde cero, toda la escala de valores que envuelve al plagio en el net art prohíbe cualquier retorno a un nivel cero de nociones" ${ }^{40}$. Así, el netactivismo generó movimientos con una metodología de actuación en grupo y un ideario político crítico. Este concepto fue iniciado por el grupo de activistas zapatistas mexicanos en 1994, divulgado por el grupo Critical Art Ensemble y con acciones como FloodNet, del grupo Electronic Disturbance Theater (EDT) ${ }^{41}$.

También, podemos diferenciar entre net art y web art. Esta última son obras que utilizan un formato de página web. Asimismo, pueden ser interactivas (net-specific) o no. En este sentido se advierten dos corrientes: la tendencia estetizante informalista, que son obras cerradas, donde normalmente se desarrollan juegos visuales y pueden contemplarse sin conexión a Internet y/o copiadas a otros soportes (CD-Rom, tarjetas de memoria, etc.), y por otro lado, proyectos participativos, donde se invita al usuario a enviar información o datos, formando parte de la obra (como File Room de Muntadas; The longest sentence of the world, de Douglas Davis o Humanos de Lilia Pérez ${ }^{42}$.

Por otro lado, con la aparición de la web 2.0 se fomentaron servicios para compartir fotografías o videos (por ejemplo, Flickr, Youtube, Vimeo, etc.), permitiendo la generación de contenido a cualquier persona, sin necesidad de conocimientos profundo en informática. Además, los artistas han encontrado multitud de contenido para obras basadas en la reutilización de imágenes, como ya hacían los artistas pop y situacionistas con sus Détournements o "Tergiversaciones" $"$.

No obstante, hay que relativizar estas distinciones, puesto que muchas obras resultan del cruce de distintas manifestaciones.

40 BERRY, Josephine, "Código al descubierto..., opus cit., p.7.

${ }_{41}$ GIANNETTI, Claudia, "Breve balance de..., opus cit.

42 GIANNETTI, Claudia, "Breve balance de..., opus cit.

43 LÓPEZ MARTÍN, Elena. y MORGADO AGUIRRE, Borja, "Estrategias artísticas..., opus cit., pp. 168-169.

\section{Aproximación a la conservación del arte de Internet}

El Plan Nacional de Conservación del Patrimonio Cultural del Siglo XX amplió el concepto de análisis de las artes plásticas y visuales. Así, pone el énfasis en la representatividad testimonial de las manifestaciones y no sólo de la condición vanguardista ${ }^{44}$. En este sentido, la evolución de los "movimientos artísticos del siglo XX ha ido desde la interrelación entre artista y espectador hacia la pérdida del interés por el objeto artístico en sí, y desviándolo al concepto o mensaje a transmitir, además, una revalorización de la acción, de la manifestación espontánea y de lo efímero, así como un incremento en la utilización y combinación de los diferentes medios" ${ }^{45}$.

El Plan Nacional también establece unos criterios de valoración y selección ${ }^{46}$ :

- Valores intrínsecos o inherentes: Técnico (soluciones innovadores y excelencia en la ejecución); cultural y estético (belleza formal, capacidad de expresión de sentimientos, emociones e ideas y la plasmación de la concepción de la realidad por parte del autor mediante recursos perceptibles por los sentidos).

- Valores sociales o culturales: expresión de tendencias relevantes; excepcionalidad, originalidad y novedad de la obra en su contexto cultural, social, temporal y geográfico.

Así, la conservación y preservación del Patrimonio Cultural del siglo XX "contribuye a la comprensión de la historia, los avances tecnológicos y sociales, así como otros fenómenos" ${ }^{47}$. No obstante, los principales problemas de conservación derivan de la falta de reconocimiento social como patrimonio a preservar, ya que no siempre reciben la atención de las administraciones públicas, al no estar enmarcados dentro las clasificaciones tradicionales, y la obsoles-

44 CARRIÓN GÚTIEZ, Alejandro (Coord.), Plan Nacional de Conservación del Patrimonio Cultural del Siglo XX, Ministerio de Educación, Cultura y Deporte, Madrid, 2015.

45 CARRIÓN GÚTIEZ, Alejandro (Coord.), Plan Nacional de..., opus cit., p.15.

46 CARRIÓN GÚTIEZ, Alejandro (Coord.), Plan Nacional de..., opus cit., p.19.

47 CARRIÓN GÚTIEZ, Alejandro (Coord.), Plan Nacional de..., opus cit., p.5. 
cencia de los medios tecnológicos por y para los que fueron creados ${ }^{48}$.

Las obras de arte de Internet contienen un binomio de inmaterialidad-materialización. Es decir, la obra, compuesta en esencia de una codificación digital más una idea conceptual, necesita de elementos tecnológicos (y si apuramos, de la interacción para que aparezca en pantalla) para materializarse. Así, podrían considerarse dos vías de trabajo: por un lado, la conservación del código, de la información, y por otro, de las condiciones de descodificación y su traducción visual ${ }^{49}$. En palabras de Annet Dekker, la conservación del arte de Internet "debe centrarse en el desarrollo y mantenimiento del futuro del trabajo, en lugar de conservar eventos pasados" ${ }^{50}$.

\subsection{El archivo y documentación como es- trategia de conservación}

El concepto de archivo y documentación del arte de Internet implica comprender cómo articulamos el valor e importancia de los acontecimientos. Se pueden recoger textos, imágenes estáticas o en movimiento, sonidos... pero también se puede documentar "interacciones, experiencias, transformaciones, reconstrucciones y variaciones, incluso percepciones asociadas a una obra determinada" ${ }^{51}$. De esta manera, la materialidad queda relegada a un segundo plano, en el intento de conservar la experiencia de los testigos.

Ed Halter ${ }^{52}$, propone tres principios para el archivo y musealización de "objetos inmateriales":

- "Poseer" arte de Internet implica la responsabilidad de darle alojamiento (hosting), es decir, se convierte en un acto de mecenazgo.

- El coleccionista participa en el proceso de confección de lo inmaterial.

${ }_{48}$ CARRIÓN GÚTIEZ, Alejandro (Coord.), Plan Nacional de..., opus cit., pp.10-11.

49 RIVERO MORENO, Luis D., "Inmaterialidades..., opus cit., p. 232.

50 DEKKER, Annet, Collecting and Conserving Net Art. Moving beyond Conventional Methods, Routledge, New York, 2018, p. 165.

51 ALSINA, Pau y HOFMAN, Vanina, "Agencia, y Materialidad en la Documentación del Arte de los Medios", en Icono, Volumen 12, n 14, 2014, p. 59. DOI: 10.7195/ ri14.v12i2.705.

52 HALTER, Ed, The rematerialization of art, 2008, [en línea] recuperado de: http://rhizome.org/editorial/287.
- Poseer arte de Internet implica la responsabilidad de preservarlo, emularlo y documentarlo.

Las estrategias de conservación tienden hacia la documentación de las obras. Para De$\mathrm{kker}^{53}$, la documentación tiene una triple dimensión: La documentación como proceso, que ofrece una idea del desarrollo del trabajo y recoge los factores importantes para la toma de decisiones; la documentación como presentación, que abarca los documentos para explicar y comunicar el trabajo (notas, mapeo, descripción escrita, fotografía, video) y que proporcionan una idea más completa de cómo era; la documentación como recreación, que tiene como objetivo conservar el potencial y la importancia del arte en vivo y debe enfrentarse a la naturaleza efímera de la obra o la complejidad técnica de obras colaborativas o conceptualmente heterogéneas. Desde esta perspectiva, la documentación como presentación se entiende como un modo de producción, así como un modo de interpretación crítica, que ayuda a superar la fragmentación inherente a la documentación

No obstante, el Plan Nacional establece criterios específicos ${ }^{54}$ :

- Identificación, registro, digitalización y catalogación de las colecciones y archivos personales de figuras relevantes del arte (artistas, críticos, historiadores, galeristas, etc.).

- Recomendación de encuestas o entrevistas a los artistas para registrar materiales, técnicas y criterios para futuras intervenciones sobre su obra.

- Consideración individualizada (estudio multidisciplinar pormenorizado).

- Investigación multidisciplinar en referencia a los nuevos materiales y métodos no tradicionales utilizados por el creador.

- Mantenimiento de la integridad conceptual y material de la obra.

- Adopción de medidas específicas de conservación, que contemplen la recuperación de los aspectos materiales y conceptuales en conservación y restauración.

- La dualidad de materia y concepto puede implicar no sólo la conservación del objeto en el tiempo, sino también el mante-

\footnotetext{
3 DEKKER, Annet, Collecting and Conserving ..., opus cit., pp. 41-48.

54 CARRIÓN GÚTIEZ, Alejandro (Coord.), Plan Nacional de..., opus cit., pp.23-24.
} 
nimiento o la recuperación del mensaje, de su significado.

Pero la exhaustividad de la documentación no garantiza una conservación de la obra de arte íntegra. En última instancia, el archivado se realiza en un soporte físico y estable, que desencadena otros problemas de conservación del arte de Internet. Además, salvaguardar una obra de arte viva y activa puede llegar a ser irrealizable ${ }^{55}$.

Por otro lado, para Ernst ${ }^{56}$, las máquinas han sido ignoradas en los estudios de arte de los Nuevos Medios. Sin embargo, existen ejemplos de la importancia compartida de los elementos físicos. Así, La Máquina Podrida es el ordenador portátil del artista Brian Mackern entre 1999 y 2004. Decidió subastar el ordenador y su contenido (que incluía sus obras y una colección de trabajos pioneros de net art). Fue adquirida por el Museo Extremeño e Iberoamericano de Arte Contemporáneo (MEIAC). Todo este proceso quedó documentado ${ }^{57}: \mathrm{Ma}-$ nifiesto de la subasta; sitio donde se efectuó la subasta; recibo de compra; protocolo de encendido y cuidados de La Máquina Podrida; videos y sonidos del encendido, apagado y del cooler, incluso un video donde Vuk Cosic intenta recuperar, desde la Máquina Podrida a su lápiz de memoria, una obra suya que había perdido.

En definitiva, hay que tener en cuenta la integridad de la obra desde el punto de vista físico, estético, la intencionalidad del artista y el contexto de la obra ${ }^{58}$. En este sentido y con el ejemplo de La Máquina Podrida, se recogen los desperfectos y las medidas de precaución en el uso del ordenador. Del mismo modo, se describen y localizan las pegatinas del mismo. En cuanto a la información y medidas de conservación y restauración, el ordenador fue "congelado" para preservar toda la información que contiene que fue traspasada a un kit de restauración formado por cuatro DVDs con la copia espejo del disco duro.

55 RIVERO MORENO, Luis D., "Inmaterialidades..., opus cit., p. 231.

56 ERNST, Wolfgang, "Media Archaeography. Method and Machine versus History and Narrative of Media", en Media Archaeology. Approaches, Applications and Implications, University of California Press, Los Angeles, 2011, pp. 239-255.

57 Subasta de la máquina podrida docs, (s.f.), [en línea] recuperado de: http://podrida.netart.org.uy/

58 GIANNETTI, Claudia, "La conservación del Patrimonio digital", en Mus-A: Revista de los museos de Andalucía, $\mathrm{n}^{\circ} 8,2007$, p. 150 .
Para Elsa Armentia ${ }^{59}$, el net art es heredero de la problemática de documentación y musealización de movimientos de vanguardias como el Dadá, y posteriormente, con el arte conceptual y el procesual: se ha pasado de la desmaterialización del objeto artístico a la inmaterialidad.

El carácter temporal y procesual del net art hace necesario el planteamiento de cuestiones éticas de su archivo y conservación. Existen una serie de cuestiones que influyen en la metodología de conservación del arte de Internet ${ }^{60}$ :

- la obsolescencia de los medios (software y hardware). El planteamiento de actualización de las obras abre la posibilidad de desvirtuar la obra con la renovación de los lenguajes.

- Originialidad y percepción. Determinación de la versión original, que puede ser el código, el disco duro donde se almacenó por primera vez o el ordenador en el que se creó; determinar si la velocidad de conexión modifica la percepción.

- La condición transformable de muchas obras, como es el caso del software art en open source, y la complejidad del archivo y documentación de un diseño que puede ser modificado por cada usuario.

- Falta de medios y coste de mantenimiento: como, por ejemplo, la obra de Muntadas, The File Room, formada por una gran cantidad de enlaces que necesitan un actualizado constante.

\subsection{Ejemplos de restauración de una obra de net art}

Para Fino Radin ${ }^{61}$, hay tres formas comúnmente reconocidas de restauración:

- Emulación: es la simulación de la arquitectura y los comportamientos de un viejo sistema informático, dentro de un sistema contemporáneo. El problema de

59 ARMENTIA, Elsa, "Curaduría de procesos en el ciberespacio. El museo yuxtapuesto", en Estudios de Arte, $\mathrm{n}^{\circ}$ 11, 2010, [artículo en línea], recuperado de: http:// www.aacadigital.com/contenido.php?idarticulo=323.

${ }_{60}$ ARMENTIA, Elsa, "Curaduría de procesos..., opus cit.; GIANNETTI, Claudia, "La conservación del..., opus cit., p. 150.

${ }_{61}$ FINO-RADIN, Ben, Digital preservation practices and the rhizome Artbase. Rhizome, The New Museum. Nueva York, 2011, pp. 17-19, [en línea] recuperado de: http://media.rhizome.org/blog/8332/rhizome-digital-preservation-practices.pdf. 
este procedimiento es que, con el tiempo, el emulador se volverá obsoleto en los sistemas informáticos contemporáneos.

- Migración: En este procedimiento, los archivos obsoletos de una obra de arte se convierten a un formato contemporáneo.

- Reinterpretación: Esta estrategia de restauración se utiliza cuando un software ya no se ejecuta en las infraestructuras contemporáneas y no se puede convertirlo. La reinterpretación requiere profundizar en la fuente del software y reparar cualquier causa de su obsolescencia.

No obstante, la restauración deja una metodología abierta a las particularidades de cada obra, no exenta de interrogantes: ¿reconstruir?, ¿emular?, ¿reinterpretar?, ¿documentar material secundario? ¿Cómo recrear el contexto original de la pieza? Uno de los principales inconvenientes es sesgar la esencia interactiva de las obras, si no se pueden reproducir las conexiones. Sin embargo, cada estrategia puede contener riesgos que influyen en su conservación: La copia a otros dispositivos (migración) puede desencadenar pérdidas de información en el proceso; la emulación, que pretende reproducir la experiencia original del entorno obsoleto, desvirtúa de alguna manera su contexto primario; la reinterpretación, que trata de prolongar la intención primaria en otros soportes, cuestiona la autenticidad de la obra; la recreación puede producir pérdidas en la idea original ${ }^{62}$. Así, para la conservación, restauración, archivo, documentación y presentación de las obras de arte de Internet, se necesitan estudios sobre la obsolescencia de los sistemas tecnológicos y su adaptación al presente y futuro, métodos para almacenar, codificar, comprimir, desmagnetizar, digitalizar, duplicar, emular, encapsular, instalar, emigrar, reinterpretar, reproducir o restaurar ${ }^{63}$.

De esta forma, destacamos la exposición en línea Net Art Anthology de Rhizome ${ }^{64}$. Esta exposición va a ir presentando hasta 100 obras de net art, restaurando y contextualizando un proyecto cada semana, para contar la historia del net art desde la década de 1980 hasta la

62 RIVERO MORENO, Luis D., “Inmaterialidades..., opus cit., p. 232.

63 GIANNETTI, Claudia, "La conservación del..., opus cit., p. 150.

64 NEW MUSEUM Y RHIZOME, Net Art Anthology, New York, 2018, [en línea] recuperado de: https://anthology. rhizome.org/ actualidad. Para ello, utiliza simuladores para aproximar la experiencia al contexto original. También tiene como objetivo abordar la escasez de perspectivas históricas en un campo en el que incluso las obras de arte más importantes son a menudo inaccesibles. La serie asume la compleja tarea de identificar, preservar y presentar trabajos ejemplares en un campo caracterizado por una amplia participación, prácticas diversas, colaboración promiscua y estándares académicos y estéticos que cambian rápidamente, esbozando un posible canon de net art.

A continuación, se exponen varios procedimientos aplicados:

\section{A. Video reconstrucción:}

Es el caso de Reabracadabra (1985) de Eduardo Kac (Fig. 1). Este poema visual fue creado y mostrado en Videotexto (una red de telecomunicaciones pre-Internet en Brasil, implementada en 1982, ofreciendo información pública y un sistema de mensajería de usuario a usuario a través de terminales especiales). Debido a que una línea telefónica era un bien escaso y valioso en Brasil en ese momento, éstos estaban disponibles principalmente en espacios públicos como bibliotecas o tiendas. Cuando la señal Videotexto se apagó, a mediados de la década de 1990, Reabracadabra se hizo inaccesible. El trabajo ha sido reconstruido en video ya que la red de la que formaba parte no existe.

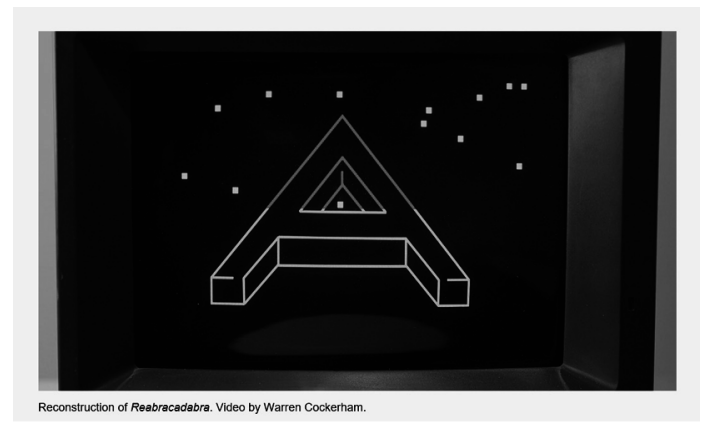

Figura 1. Video reconstrucción de Reabracadabra por Warren Cockerham. (Recuperado de: https://anthology.rhizome.org/ reabracadabra)

\section{B. Reproducción:}

En 1994, la artista y poetisa australiana Mez Breeze desarrolló un lenguaje en línea que denominó Mezangelle. Utilizando el lenguaje de programación y el habla informal, Mezangelle reorganiza el idioma (inglés estándar) para 
crear un significado nuevo e inesperado (Fig. 2). Así, contribuyó con correos electrónicos del servidor de listas 7-11, dedicados a la experimentación en net art. La obra presentada para esta exposición, dispone de una suscripción para recibir cuarenta y tres correos electrónicos re-ejecutados en el mismo orden y ritmo que su transmisión original.

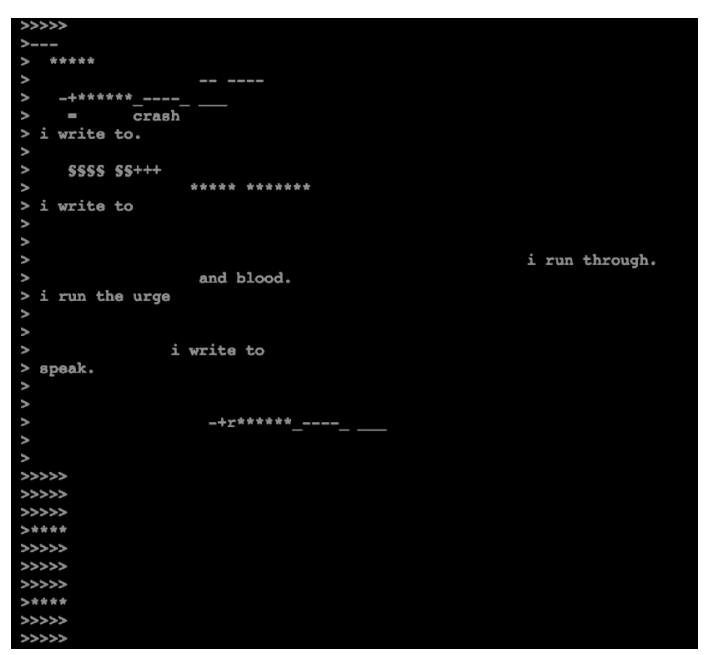

Figura 2. Captura de pantalla de Mez Breeze, 4-7 5-kc5, correo electrónico de 7-11 email list, 1998. (Recuperado de: https://anthology.rhizome.org/mez-breeze)

\section{Restauración:}

Brandon de Shu Lea Cheang. 1998 - 1999 (Fig. 3). El proyecto comenzó con dos artículos que Cheang leyó en Village Voice. Uno, relataba la historia de Brandon Teena, un joven transexual de Nebraska que fue brutalmente asesinado. El otro, "Una violación en el ciberespacio" de Julian Dibbell, que describía una ola de violación en una sala de chat de sólo texto, y que sin embargo dejaba a las víctimas sintiéndose violadas y privadas de seguridad. Al establecer una conexión entre estos episodios muy diferentes de violencia, Cheang comenzó un proceso de investigación de varios años para crean un proyecto de narrativa web.

Brandon se programó utilizando tecnologías web actuales, como los (applets de Java, scripts CGI, JavaScript, HTML, PHP). Casi dos décadas después, algunas de estas tecnologías ya no son compatibles con navegadores contemporáneos, y algunas partes de se habían corrompido o eran inaccesibles (texto e imágenes animadas que no se mostraban correctamente; tipos de letra, tamaños y colores interpretados incorrectamente; enlaces rotos, etc.).

El objetivo de la restauración era restablecer la experiencia e interactividad en línea de

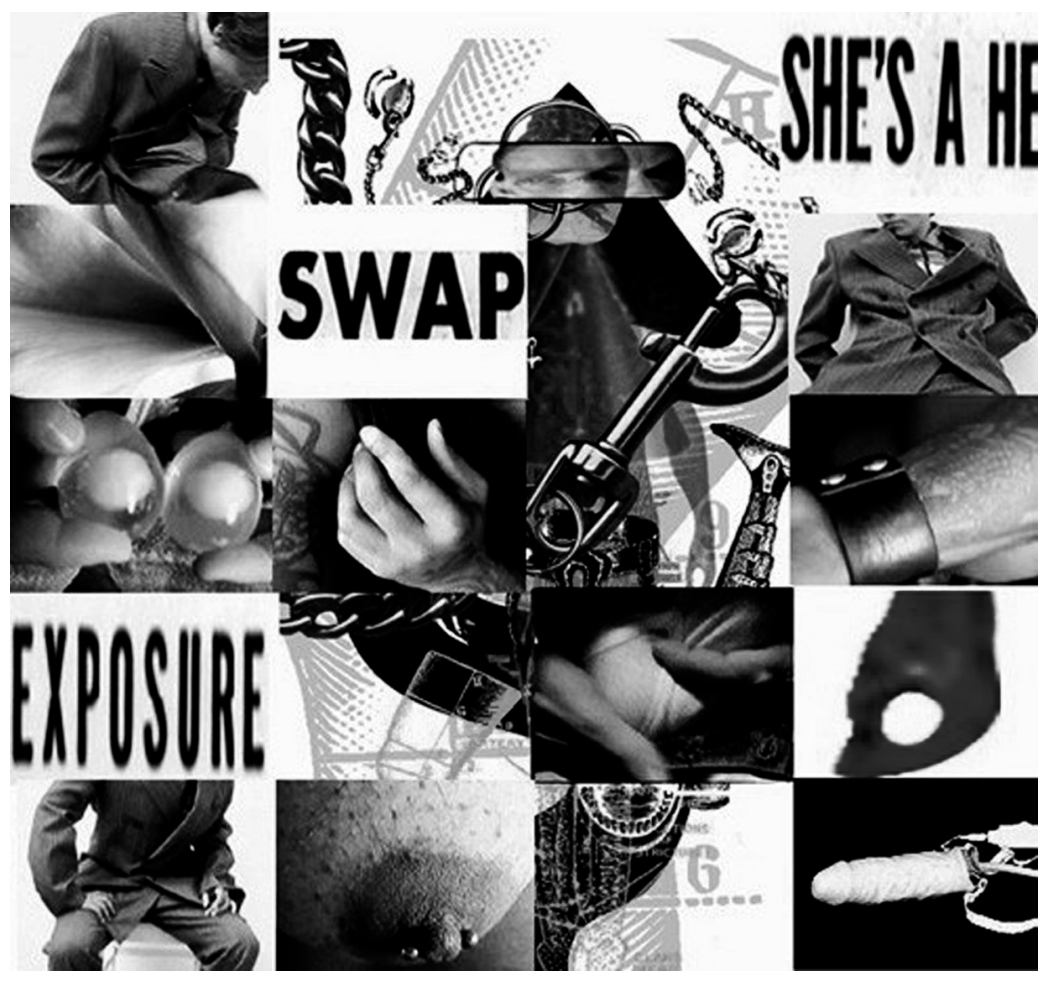

Figura 3. Brandon de Shu Lea Cheang, tras la restauración de 20162017. (Recuperado de: http:// brandon gugegenheim.org/credits/interface/bigdoll/index. html) 
Brandon, preservando todos los comportamientos funcionales y las propiedades estéticas del trabajo tal como se define en el código fuente original. No se eliminó ningún código original. Cada adición fue documentada a través de la anotación de código fuente, control de versión y reporte de tratamiento ${ }^{65}$.

Brandon hace uso de ventanas emergentes. Así, para experimentarlo como se pretendía originalmente, los usuarios deberían deshabilitar el bloqueo de ventanas emergentes en sus navegadores web. Además, fue diseñado para ser visto en ordenador de escritorio o portátiles y no para tabletas, teléfonos móviles u otros dispositivos con pantalla táctil ${ }^{66}$.

\section{Emulación:}

97

Olia Lialina. 1996. My Boyfriend Came Back from the War (Fig. 4). El trabajo cuenta la historia de una mujer joven que se reencuentra con su novio después tras regresar de un conflicto lejano. My Boyfriend Came Back from the War resalta los paralelismos y las divergencias entre el cine y la web como medios artísticos y de masas y explora el lenguaje entonces emergente de la red. Para su restauración, se ha emulado el navegador Netscape.

The web Stalker de I / 0 / D (Matthew Fuller, Colin Green, Simon Pope), 1997 (Fig. 5). Web Stalker era un navegador creado por artistas

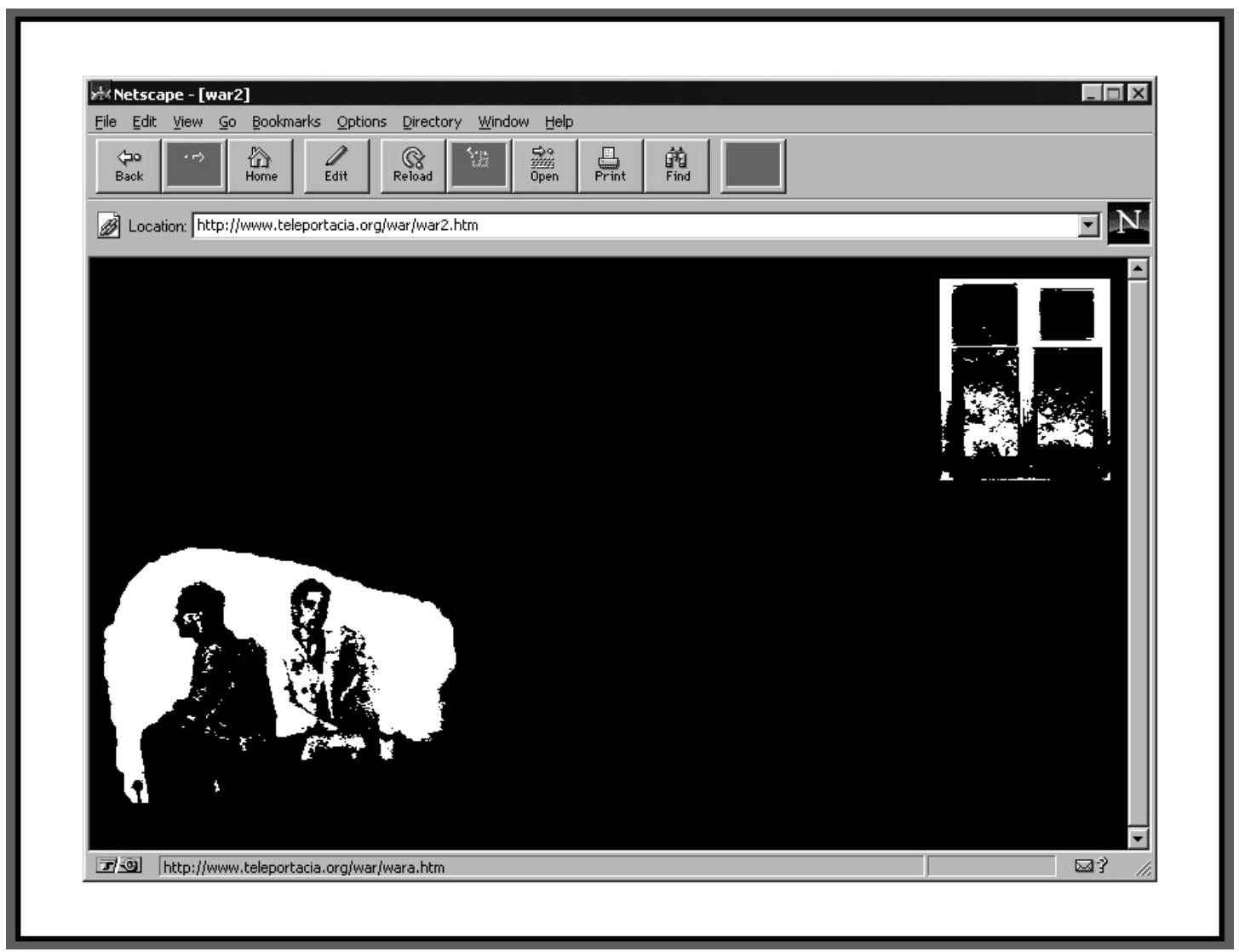

Figura 4. My Boyfriend Came Back from the War de Olia Lialina (1996). (Recuperado de: https://anthology.rhizome.org/my-boyfriend-cameback-from-the-war)

65 THE GUGGENHEIM MUSEUMS AND FOUNDATION, Brandon. 2016-2017 Restoration, New York, 2017, [en línea] recuperado de: http://brandon.guggenheim.org/ credits/

66 NEW MUSEUM Y RHIZOME, Net Art Anthology..., opus cit. 


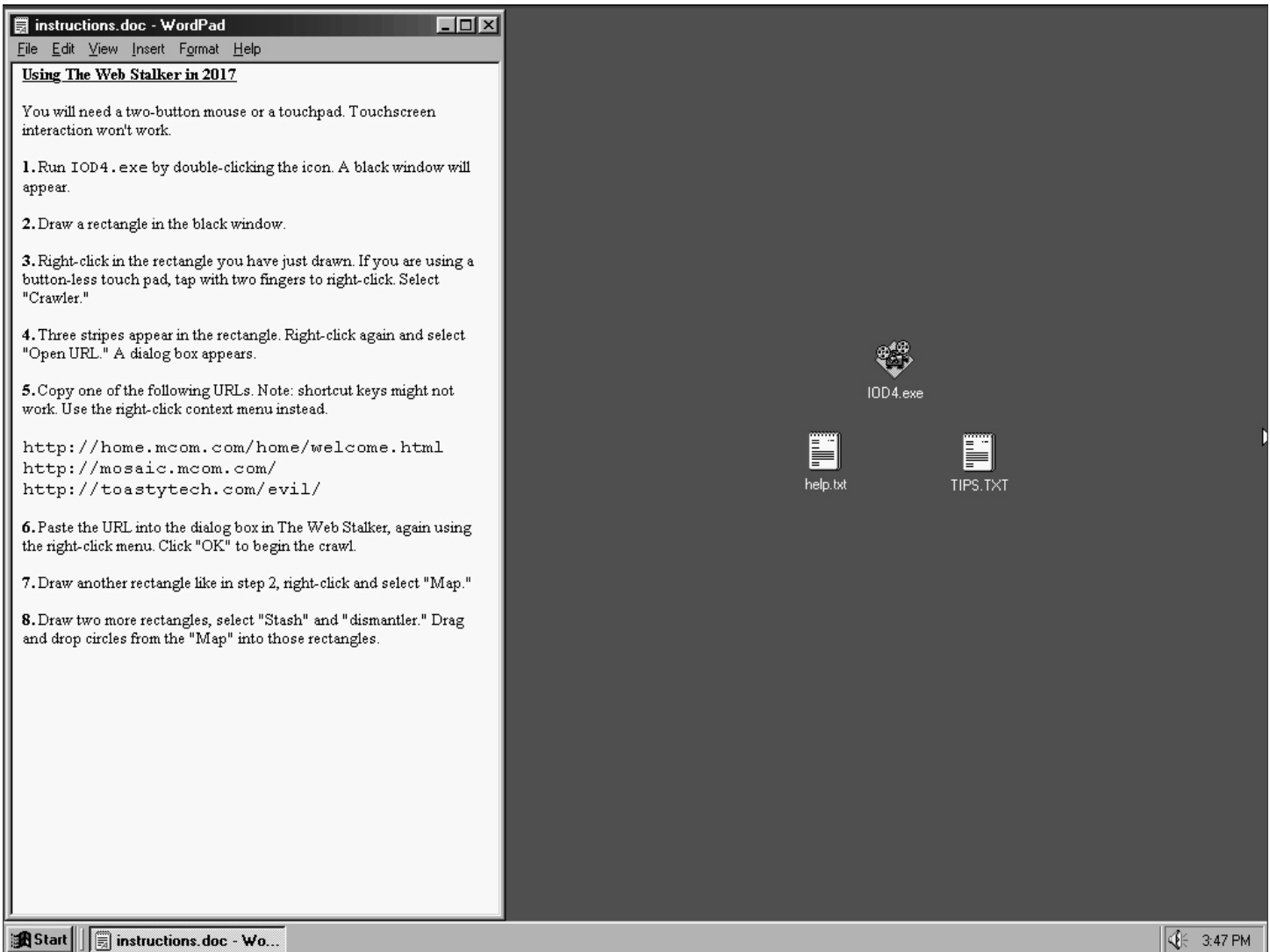

Figura 5. The web Stalker. I / O / D (1997). (Recuperado de: https://anthology.rhizome.org/the-web-stalker)

que desafiaba las convenciones emergentes del nuevo medio de la web. Lanzado en un momento en que Netscape Navigator y Microsoft Internet Explorer compitieron por el dominio, criticó a estos navegadores comerciales por alentar modos de navegación pasivos y restrictivos. La interfaz de The Web Stalker ignoraba las imágenes y el formato, y en su lugar permitía a los usuarios moverse libremente entre los textos en línea, al tiempo que resaltaba las conexiones entre ellos. Para su restauración se ha emulado el sistema operativo desde donde lanzar este navegador.

\subsection{Algunos proyectos de recopilación y documentación del media art}

La concepción de archivo está transitando desde el organismo del Estado al archivo cotidiano, colectivo y expansivo en el contexto de Internet. Así, destacamos el proyecto Internet Archive Project (www.archive.org), el uso de las folcosonomias o el proyecto Forging the Future, abriendo cuestionario de preservación del $\mathrm{Va}$ - riable Media Project y la participación crowsourcing (www.forging-the-future.net) ${ }^{67}$.

The Daniel Langlois Foundation for Art, Science, and Technology (http://www.fondation-langlois.org/), con la colaboración de diversas instituciones internacionales, desarrolla un extenso proyecto que abarca tres áreas: historia tecnológica; documentación contextualizada que permita comprender el periodo en el que se realizó la obra; y desarrollo de protocolos y técnicas de preservación y restauración ${ }^{68}$. En 2002, junto al Museo Guggenheim, crearon Variable Media Networks (http://www.variablemedia.net/), donde se estudian nuevas estrategias de conservación y analizan los problemas de la documentación inadecuada o la obsolescencia de la tecnología utilizada.

Media_art_net desarrollado por el ZKM y el Goethe Institut (http://www.medienkunstnetz. de/), dispone de información y documentación

67 ALSINA, Pau y HOFMAN, Vanina, “Agencia y Materialidad..., opus cit., p.61.

68 GIANNETTI, Claudia, “La conservación del..., opus cit., p. 150. 
audiovisual sobre el media art (historia, tendencias temáticas, artistas, obras, especialistas, etc.).

En 2001, Martin Wattenberg crea Idealine, como respuesta a una petición del Whitney Museum of American Art de Nueva York (http://whitney.org/arport/commissions/idealine.shtml). El proyecto consiste en una compilación de obras realizadas para la web entre 1995 y el 2002, aportadas por una usuarios de listas de correos electrónicos relacionados con el arte, a los que se les mandaba una solicitud. Wattenberg las etiquetó por categorías según títulos, temas y tecnologías de las piezas.

Rhizome (http://rhizome.org/) es una plataforma que defiende el arte y la cultura nacidos en el mundo digital a través de comisariados, exhibiciones, preservación digital y desarrollo de software. Fue fundado por el artista Mark Tribe y desde 2003 está afiliada a The New Museum.

\subsection{Autenticidad conceptual del arte de Internet}

A los pioneros del net art les interesaba las posibilidades del medio: la autogestión, la condición inmaterial del arte, el cuestionamiento de la autoridad de las instituciones y de las categorias de artista y obra de arte, la indistinción entre original y reproducción en la red (defendieron una producción independiente y pública ${ }^{69}$. Estas características forman parte del espíritu original del arte de Internet.

Por otro lado, Jacob Lillemose reflexiona, a partir de las teorías de Jean-François Lyo$\operatorname{tard}^{70}$, sobre la condición inmaterial del arte de Internet. Concluye que es un nuevo tipo de materialidad basada "en relaciones comunicativas y manejo de información en lugar de propiedades físicas"71, es decir, lo digital representa una nueva cualidad material ${ }^{72}$. Así, por ejemplo, al publicar un contenido en Youtube,

69 ARMENTIA, Elsa, "Curaduría de procesos..., opus cit.

70 LYOTARD, Jean-Francois, "Les Immatériaux", en Thinking about exhibitions, Routledge, New York, 1985, pp. 159-175.

71 LILLEMOSE, Jacob, “Conceptualizing Materiality - art from the dematerialization of the object to the condition of immateriality", en Symposium Curating new media art, 2005, [en linea] recuperado de: http:// umintermediai501.blogspot.com/2008/01/conceptualizing-materiality-art-from.html

72 ARMENTIA, Elsa, "Curaduría de procesos..., opus cit.; ALSINA, Pau y HOFMAN, Vanina, "Agencia y Materialidad..., opus cit., p.64. éste desarrolla una dinámica de enriquecimiento con votaciones, comentarios, apropiaciones, tergiversaciones $\mathrm{u}$ otras respuestas que transforman el contenido original: la obra ya no es un elemento unidireccional e inamovible, sino que madura en su proceso de vida en Internet ${ }^{73}$. Internet ha proporcionado una inmensa capacidad de interacción como elemento necesario para la construcción de la obra y ha impulsado al usuario como creador de material reciclable digital $^{74}$. De esta forma, podemos decir, que la interacción comunicativa es otro de los pilares del significado de este tipo de manifestaciones.

En definitiva, la obra ha de entenderse como obra abierta, es decir, "un acto de comunicación que tiene lugar a través del empleo de unos canales y códigos y que sólo se completa con la llegada del mensaje-información al receptor"75. Del mismo modo, el trabajo con relaciones y procesos, disuelve la noción de autoría única, objetos finales o tiempo continuo ${ }^{76}$.

Asimismo, el funcionamiento de un ordenador está íntimamente ligado al concepto de copia de la información (la web que vemos es una copia de los archivos del servidor por el navegador). Así, la idea tradicional de original se caduca puesto que no se pueden distinguir las copias de su original ${ }^{77}$. El ordenador tiene una capacidad de seducción basada en la proximidad del individuo al objeto (pantalla, teclado...) y constituirse como herramienta personal de trabajo y/o medio de interrelacionase con otras personas ${ }^{78}$. Con lo cual, el soporte físico también juega un papel protagonista en el momento de definir qué elementos son necesarios para delimitar la autenticidad del arte de Internet. Algunas instituciones, como Foundation for the Conservation of Modern Art y Netherlands Institute for Cultural Heritage (1999), han reflexionado sobre la autenticidad en la conservación y restauración del arte moderno y contemporáneo. Así, propone la evaluación de la apariencia perceptible, el proceso de pro-

\footnotetext{
73 LÓPEZ MARTÍN, Elena. y MORGADO AGUIRRE, Borja, "Estrategias artísticas del..., opus cit., p. 174.

74 LÓPEZ MARTÍN, Elena. y MORGADO AGUIRRE, Borja, "Estrategias artísticas del..., opus cit., p. 174.

75 RIVERO MORENO, Luis D., "Inmaterialidades..., opus cit., p. 229.

76 DEKKER, Annet, Collecting and Conserving ..., opus cit., p. 163.

77 BERRY, Josephine, “Código al descubierto..., opus cit., p.4.

78 LÓPEZ MARTÍN, Elena. y MORGADO AGUIRRE, Borja,
} "Estrategias artísticas del..., opus cit., p. 167. 
ducción sobre el significado de una obra y si éstos se ven influenciados por los trabajos de conservación y restauración.

Frente al concepto de conservación, Rivero Moreno $^{79}$ plantea el concepto de continuidad, y establece las siguientes condiciones:

- conservar el contenido en una forma que el creador reconozca como suya

- que sea utilizable y comprensible para un usuario final

- proporcionar un contexto suficiente para explicar las circunstancias de creación, uso y continuidad del documento

- creación de una estructura, original o no, que permita que el contenido y el contexto sigan siendo reproducibles y utilizables.

\section{Conclusiones}

Las manifestaciones de arte contemporáneo poseen una relación difusa entre materia, técnica y significado. Dicho significado, además, puede ser particular para el artista o evolucionar y completarse con el usuario/espectador. Del mismo modo, el arte de Internet aporta sus propias características: una producción basada usualmente en códigos abiertos, una puesta en escena que se apoya en la participación y un sistema de distribución de carácter evolutivo a través de redes y enlaces. Así, todo mecanismo de conservación que infiera con la identidad material de la obra, puede alterar su significado.

En este sentido, es necesario determinar si el estado de conservación es compatible con el significado de la obra de arte y si la estrategia de conservación-restauración mantiene dicho significado. Hay que destacar, que algunos artistas no les interesan la perspectiva del futuro o su producción se dirige a crear un conjunto de relaciones y procesos (cuyo límite tiende al infinito).

En particular, los principales problemas de conservación del arte de Internet son:

79 RIVERO MORENO, Luis D., “Inmaterialidades..., opus cit., p. 234.
- Riesgo de obsolescencia, tanto de software como de hardware.

- Plagio, facilidad y normalidad en el hecho copiar.

- Pérdida de autenticidad (eliminación de conectividad entre usuarios...)

El archivo y la documentación se reconocen como la manera de conservar el arte de Internet. Destacamos el aumento y desarrollo tanto de iniciativas (Variable Media Network; Capturing Unstable Media; Archiving the Avantgarde; DOCAM; Planets Project; KEEP, etc.) como de técnicas (web harvesting).

Los conceptos tradicionales de la conservación-restauración no alcanzan a recoger la idiosincrasia de las obras de arte de Internet. Por un lado, existe la necesidad de conservar la información, y por otro, la exigencia de la arqueología de los medios, de la importancia de los dispositivos y del contexto físico de creación y recepción de las obras. No obstante, los organismos competentes del Estado deben coordinar la preservación del patrimonio digital, en general. Además, hay que involucrar a fabricantes de equipos y programas informáticos a colaborar con las instituciones que se ocupen de conservar y restaurar el patrimonio digital. Asimismo, para las peculiaridades del arte de Internet, es necesario un "navegador de calidad de museo que se ejecute en infraestructuras contemporáneas y proporcione soporte heredado para protocolos arcaicos y marcado de los primeros días del arte de Internet" ${ }^{\circ 0}$.

La UNESCO ${ }^{81}$, en sus comunicados, atiende a la noción de preservación digital y establece que "la mayor amenaza para la continuidad digital es la desaparición de los medios de acceso. No puede decirse que se han conservado los objetos digitales si, al haber dejado de existir los medios de acceso a ellos, resulta imposible utilizarlos. El objetivo de la preservación de los objetos digitales es mantener su accesibilidad, es decir, la capacidad de tener acceso a su mensaje o propósito esencial y auténtico".

\footnotetext{
$\overline{80}$ FINO-RADIN, Ben, Digital preservation practices..., opus cit., pp. 17-18.

81 UNESCO, Noción de preservación digital, 2017, [en línea] recuperado de: http://www.unesco.org/new/es/ communication-and-information/access-to-knowledge/preservation-of-documentary-heritage/digital-heritage/concept-of-digital-preservation/
} 